\title{
Intracavitary tumor spread of a metastatic testicular seminoma in the left atrium and ventricle
}

\author{
Joerg Linneweber, MD, ${ }^{\mathrm{a}}$ Ahmed Magheli, MD, ${ }^{\mathrm{b}}$ Alexander Lembcke, MD, ${ }^{\mathrm{c}} \mathrm{T}$. Christ, MD, ${ }^{\mathrm{a}}$ and \\ W. Konertz, MD, $\mathrm{PhD}^{\mathrm{a}}$
}

With an incidence of less than $0.02 \%$, primary tumors of the heart are rare. ${ }^{1}$ Most of the primary heart tumors are benign, with about $50 \%$ being myxomas, ${ }^{2}$ and intracavitary growth (predominantly in the left atrium) is frequently observed. Secondary or metastatic heart tumors occur much more frequently. Intracavitary growth of secondary heart tumors, however, is unusual. Almost all types of tumors have been occasionally described to spread to the heart, but metastatic heart tumors only rarely gain clinical attention because symptoms of disseminated tumor disease usually prevail. Metastatic tumors can involve the heart by means of direct invasion, hematogenous spread, and lymphatic spread. Sometimes tumors also spread to the heart through intracavitary extension. We report the case of a 20 -year-old man who presented with metastatic testicular seminoma and intracardiac tumor spread from a pulmonary metastasis.

A 20-year-old man with significant metastatic testicular cancer was transferred to our institution for further evaluation and treatment. Briefly, the patient had undergone inguinal orchiectomy a few weeks earlier for a mixed germ cell tumor (seminoma and teratoma) of the right testis and was treated with adjuvant chemotherapy (cisplatin, etoposide, and bleomycin), which had to be discontinued because of massive pulmonary embolism, pancytopenia with sepsis, and a newly diagnosed mass in the left atrium and ventricle. At the time of admission, he had pulmonary metastases bilaterally and retroperitoneal bulky disease.
A transthoracic echocardiogram found a highly mobile mass/thrombus in the left atrium and ventricle. A subsequent computed tomographic scan revealed a greater than $10 \times 3-\mathrm{cm}$ mass originating from a $2.5-\mathrm{cm}$ solid pulmonary metastasis in the right lower lobe. The tumor invaded the right lower pulmonary vein and extended through the left atrium into the ventricle. In addition, a 6-mm cardiac metastasis with intracavitary growth was revealed at the septum of the left ventricle (Figure 1).

The patient was transferred for urgent cardiac surgery. At the time of the operation, the protruding mass was removed through a left atriotomy, extending the incision into the right lower pulmonary vein. The intracavitary left ventricular metastasis at the septum of the left ventricle was approached through a transverse aortotomy and resected through the aortic valve. Pathological and histochemical examination of the specimen described a partly organized thrombus with atypical glandular cells representing metastatic teratoma (Figure 2).

The patient had an uncomplicated operative and postoperative course and was transferred for further chemotherapy. A postoperative echocardiogram showed no residual intracavitary tumor.

\section{References}

1. Reynen K. Frequency of primary tumors of the heart. Am J Cardiol. 1996;77:107. 2. Reynen K. Cardiac myxomas. N Engl J Med. 1995;333:1610-7.

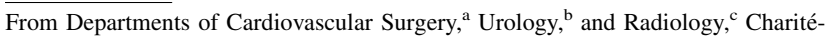
Universitätsmedizin Berlin, Germany.

Disclosures: Authors have nothing to disclose with regard to commercial support. Received for publication Sept 17, 2010; accepted for publication Sept 27, 2010.

Address for reprints: Joerg Linneweber, MD, Department of Cardiovascular Surgery, Charité-Universitätsmedizin Berlin, Charité Platz 1, 10117 Berlin, Germany. (E-mail: joerg.linneweber@charite.de).

J Thorac Cardiovasc Surg 2011;141:583-4

$0022-5223 / \$ 36.00$

Copyright (c) 2011 by The American Association for Thoracic Surgery

doi:10.1016/j.jtcvs.2010.09.045
} 

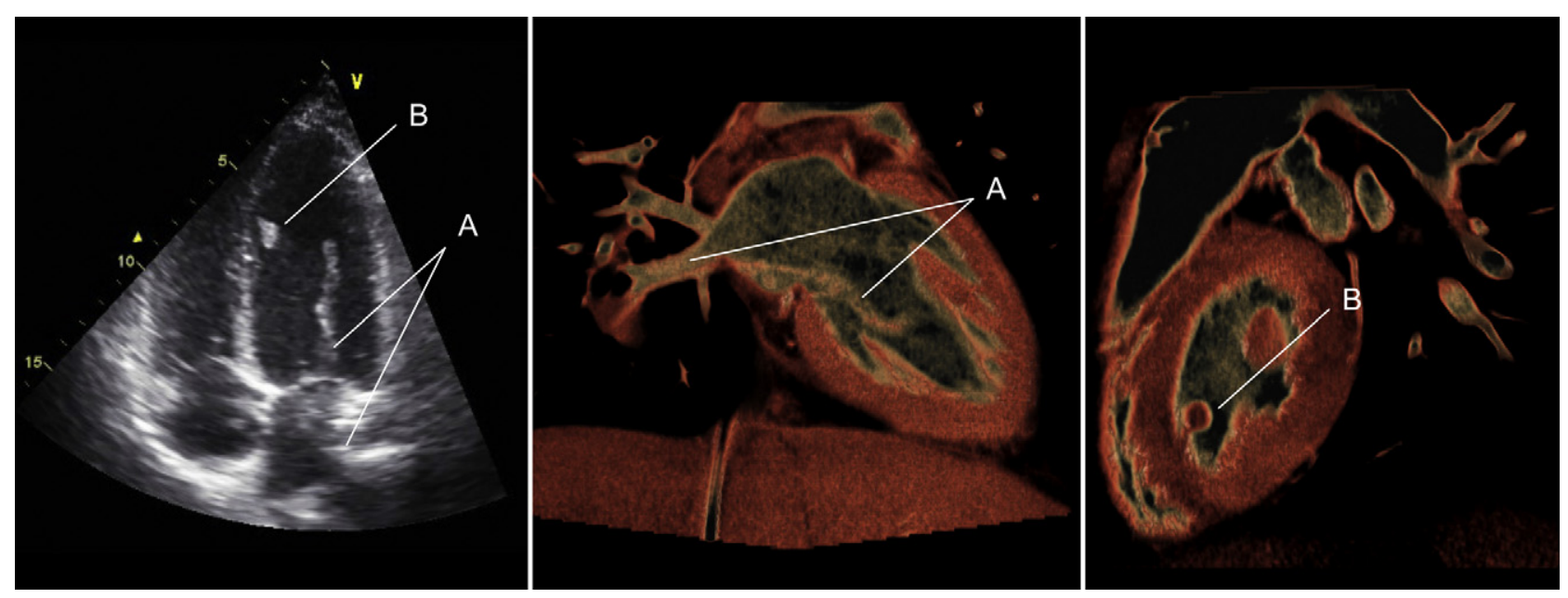

FIGURE 1. Transthoracic echocardiogram and computed tomographic scan of the heart. $A$, A $10 \times 3-\mathrm{cm}$ tumor mass in the left atrium and ventricle. $B$, A 6-mm intracavitary metastasis at the septum of the left ventricle.

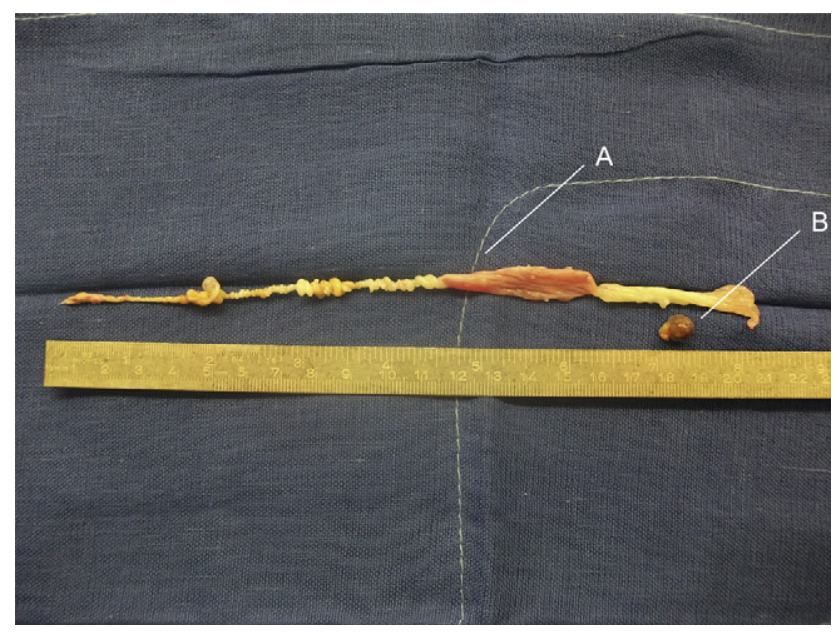

FIGURE 2. Macroscopy of the intracardiac tumor mass. $A$, Pathological and histochemical examination of the specimen described a partly organized thrombus with atypical glandular cells representing metastatic teratoma. $B$, Ventricular metastasis of the mixed germ cell tumor from the septum of the left ventricle. 